\title{
Neurologic Condition of Healthy Term Infants at 18 Months: Positive Association With Venous Umbilical DHA Status and Negative Association With Umbilical Trans-fatty Acids
}

\author{
HYLCO BOUWSTRA, JANNEKE DIJCK-BROUWER, TAMÁS DECSI, GÜNTHER BOEHM, E. RUDY BOERSMA, \\ FRITS A. J. MUSKIET, AND MIJNA HADDERS-ALGRA
}

\begin{abstract}
Department of Neurology, University of Groningen [H.B., M.H.], Pathology and Laboratory Medicine [J.D.-B., F.M.], Department of Pediatrics/Obstetrics and Gynecology [E.B.], Perinatal Nutrition and Development Unit, University Medical Center Groningen, 9700 RB, Groningen, The Netherlands; Department of Pediatrics [T.D.], University of Pécs, H-7624 Pécs, Hungary; Numico Research Germany
\end{abstract} [G.B.], D-61381 Friedrichsdorf, Germany

\begin{abstract}
Prenatal long-chain polyunsaturated fatty acids (LCPUFAs) and trans-fatty acids may affect neurodevelopment. In healthy term children, we determined relationships between relative fatty acid contents of umbilical arteries and veins and neurodevelopment at 18 mo. The study comprised a mixed group of 317 breast-fed, formula-fed, and LCPUFA formula-fed children. Study endpoints were the Hempel neurologic examination resulting in a neurologic classification and neurologic optimality score (NOS), and the Bayley Psychomotor Developmental Index (PDI) and Mental Developmental Index (MDI). Fifteen children showed minor neurologic dysfunction (MND). The umbilical vein trans, trans-18:2n-6 content was higher in children with MND than in the normal group. The NOS was significantly reduced in infants with an umbilical vein docosahexaenoic acid (DHA) content within the lowest quartile. Umbilical vein arachidonic acid (AA) was related to NOS in univariate statistics but not in multivariate analyses. The sum of trans-fatty acids and that of C18 trans-fatty acids showed a negative association with NOS in both univariate and multivariate analyses. No associations were found between AA, DHA and total trans-fatty acids with PDI or MDI. In conclusion, neonates with a relatively low DHA status and those with high trans-fatty acid levels have a less favorable neurologic condition at 18 mo. (Pediatr Res 60: 334-339, 2006)
\end{abstract}

$\mathrm{L}^{\mathrm{s}}$ ittle is known about the effects of prenatal essential fatty acid and long-chain polyunsaturated fatty acid (LCPUFA) status on long-term neurodevelopmental outcome in healthy term infants. This is remarkable because there are many indications that LCPUFAs play an important role in the development and function of the nervous system $(1,2)$. LCPUFAs, notably DHA, affect biochemical properties of cell membranes and may alter signal transduction, gene expression, and cell function in the nervous system $(1,3,4)$. Rapid accretion of LCPUFAs takes place in the infant's nervous tissue during pre- and early postnatal life when infants do not seem to synthesize sufficient amounts of LCPUFAs from their precursors to cover their high demands $(5,6)$. The exclusive source of LCPUFAs during the prenatal period is supplied from

Received February 16, 2006; accepted April 19, 2006.

Correspondence: Mijna Hadders-Algra, M.D., Ph.D., Developmental Neurology, University Medical Center Groningen; CMC-IV, 3rd Floor, Hanzeplein 1, 9713 GZ Groningen, The Netherlands; e-mail: M.Hadders-Algra@med.umcg.nl

The study was financially supported by Numico Research B.V.

DOI: 10.1203/01.pdr.0000233043.16674.1d maternal stores and maternal diet, a supply that is reflected by the LCPUFA content of the umbilical vein (7). Two recent studies indicated that the umbilical cord content of DHA, AA, and EFA is related to neurologic condition at postnatal d $10-14$ and at 3 mo $(8,9)$. Two other studies found no relationship between neonatal fatty acid status and cognitive function at 4 and $7 \mathrm{y}$ of age $(10,11)$.

Koletzko (12) found that neonatal trans-fatty acid status is inversely correlated to birth weight in preterm infants. Little is known about the effects of trans-fatty acids on development and child health, but the available data indicate that trans-fatty acids may have adverse effects because of their negative association with LCPUFA status (13-15). A review by Larqué et al. (16) indicated that trans-fatty acid intake in adults averages $2-8 \mathrm{~g} / \mathrm{d}$ ( $2.5 \%$ of total energy intake). This intake has been quite stable in the past decades due to a counterbalancing effect of more intake of hydrogenated oil and decreases in trans-fatty acid content in food (16). A report of the Dutch Ministry of Health, Welfare, and Sports indicated that adult intake of trans-fatty acids in The Netherlands in 2003 averaged $2.8 \mathrm{~g} / \mathrm{d}$ (1.1\% of total energy intake) (17). It is possible that trans-fatty acid exposure during early life may affect the infant's neurologic condition (16).

The primary aim of this study is to evaluate in healthy term infants, the relationship between the relative LCPUFA content in the umbilical wall, used as a proxy of prenatal LCPUFA status, and neurodevelopmental outcome at 18 mo of age. The secondary aim was to study the relationship between transfatty acid content in the umbilical wall and neurodevelopmental outcome at $18 \mathrm{mo}$.

\section{METHODS}

Subjects. This study is part of a double-blind, randomized, controlled trial investigating the effect of LCPUFA supplementation on neurodevelopment of healthy term infants. Details of the study design have been described elsewhere (18). Briefly, mother-infant pairs were recruited during pregnancy

Abbreviations: AA, arachidonic acid; DHA, docosahexaenoic acid; EFA, essential fatty acid; LCPUFA, long-chain polyunsaturated fatty acid; MDI, mental developmental index; MND, minor neurologic dysfunction; NOS, neurologicoptimality score; PDI, psychomotor development index 
checkup visits at various locations in and near Groningen at which time the parents provided written informed consent. Final enrollment in the study occurred in the neonatal period, at which time parents provided written informed consent. Enrollment occurred between February 1997 and October 1999. All infants were born at 37-42 wk of gestation and were of native West European origin. Excluded from the study were children with a congenital disorder interfering with adequate functioning in daily life, children from multiple births, children whose mother did not master the Dutch language or suffered from significant illness or disability, and children who were adopted and fostered. The study population comprised 474 infants. Three study groups were formed; two randomized formula groups and a breast-fed group $(n=$ 159). The control formula group $(n=169)$ received a commercially available formula (Nutrilon Premium; Nutricia, Zoetermeer, The Netherlands) for 6 mo. The LCPUFA-supplemented formula group $(n=146)$ received the same formula enriched with $0.45 \%$ AA and $0.30 \%$ DHA for 2 mo. After 2 mo, the LCPUFA-supplemented group received control formula until the age of 6 mo. Breast-feeding was done as long as possible. If breast-fed infants required formula feeding as a supplement or when breast-feeding stopped, they received LCPUFA-supplemented formula until 2 mo and control formula from 2 to 6 mo. The parents and the examiners were unaware of the type of formula that the infants received. The study was approved by the Ethics Committee of the Groningen University Hospital (MEC 95/08/207).

Analysis of fatty acids of the umbilical vessels. Permission to collect umbilical cord tissue was granted for 317 infants, i.e. $67 \%$ of the original population (Fig. 1). The umbilical cord was immediately collected after parturition. Seven- to $10-\mathrm{cm}$ samples were taken at the most proximal site of the placenta and stored in saline at $4^{\circ} \mathrm{C}$ according to established methods (19). Fatty acid methyl esters were determined by high-resolution capillary gas liquid chromatography as described by Dijck-Brouwer et al. (8) and Decsi et al. (20). Data were expressed as \% by wt of fatty acids with chain lengths of 14 to 24 carbon atoms (19). The detection limit of trans-fatty acids was one molecule among 10,000 , i.e. $0.01 \%$. A typical chromatogram of trans-fatty acids detected in our laboratory has been published (21)

Neurologic assessments at 18 mo. Follow-up at the age of 18 mo consisted of two different neurodevelopmental assessments: the neurologic examination according to Hempel and the Bayley Scales of Infant Development (BSID). Follow-up for the various developmental outcome parameters in infants for whom information on fatty acid values in the umbilical cord was available is shown Figure 1. The social and perinatal background of the infants who were included in the present analyses, and the infants without assessments or fatty acid samples are shown in Table 1 .

Each child was assessed neurologically using the technique described by Hempel (22). It measures in a standardized free-field situation motor functions (grasping, sitting, crawling, standing, and walking). In addition to the assessment of motor milestones, the quality of motor behavior is also assessed. In addition, muscle tone, reflexes and the function of the cranial nerves are assessed. Each toddler was classified as neurologically normal, showing signs of minor neurologic dysfunction (MND), or as definitely abnormal. The classification of definitely abnormal implies the presence of a distinct neurologic syndrome, which leads to severe limitations in function and social participation, such as cerebral palsy. MND implies the presence of a functional impairment that may be associated with some degree of disability. Examples are mild deviations in gross and fine motor function or mild abnormalities in muscle tone regulation or reflexes. After classification into distinct categories, we used the optimality concept to summarize the neurologic condition. The optimal range was defined from 57 items of the neurologic examination list. The NOS is the sum of the number of items with outcomes within the predefined optimal range $(23,24)$.

The BSID-II was used to assess mental and psychomotor development at the age of $18 \mathrm{mo}$ (25). The Mental Developmental Index (MDI) and the Psychomotor

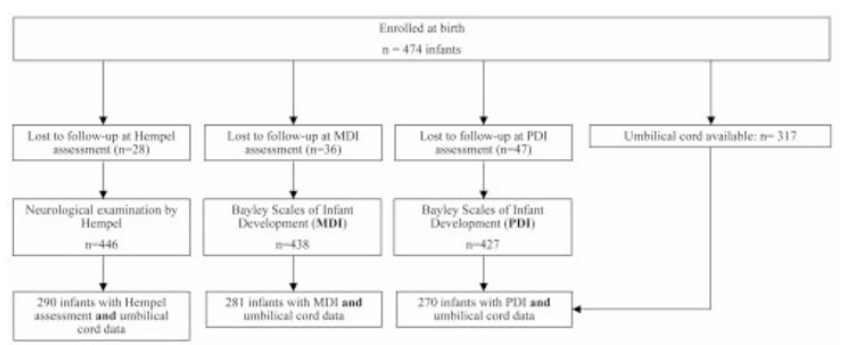

Figure 1. Flow diagram of infants included into the study and assessed at 18 mo of age. Total number of participants at enrollment: $n=474$ \{control formula group $(n=169)$, LCPUFA formula $(n=146)$, breast-feeding $(n=159)\}$.
Developmental Index (PDI) were scored based on the number of items that were successfully completed. Because the children were not exactly $18 \mathrm{mo}$ of age at the time of the assessment, we converted the scores into age-normalized values, as derived from recently developed Dutch norms (26). The MDI assesses memory, problem solving, discrimination, classification, language, and social skills. The PDI measures control of gross and fine muscle groups, including walking, running, jumping, grasping, and imitation of hand movements.

Assessment of potential confounders. Detailed and standardized information on the infants' social and perinatal conditions was collected. For the latter, we used the 74 variables of the obstetric optimality score (OOS), which range from the parents' socioeconomic status and health condition to the infant's condition immediately after birth. The sum of the number of items having outcomes within a predefined optimal range forms the OOS score (27). We used the information obtained from the OOS both as raw data dichotomized into optimal and nonoptimal categories. Besides collecting information on the parent's level of education and occupation, social condition was also assessed by the Home Observation for Measurement of the Environment (HOME) inventory (28). The importance of taking into account the role of social factors in the analyses of the relationships between neonatal fatty acid status and developmental outcome is underlined by the fact that social economic characteristics and fatty acid status in the umbilical vein are related (Table 2) (17)

Statistics. The PDI and MDI had a normal distribution. The distribution of the NOS was skewed to the left. To achieve normality, we performed the following transformation: $-\ln (58.5-$ NOS $)$. To calculate differences in fatty acid composition in umbilical vein and artery between the children with a normal neurologic condition and those with MND, we performed the MannWhitney test. The analyses focused on the relationship between the relative fatty acid contents of the umbilical wall (vein and artery) and the NOS and the Bayley MDI and PDI. Univariate nonparametric Spearman's correlations were used to calculate the correlations because most fatty acid data were nongaussian distributed. Subsequently, multivariate analyses were carried out by means of linear logistic regression analyses. This allowed elucidation of the relationship between the umbilical fatty acid content at birth and neurologic condition at $18 \mathrm{mo}$ while correcting for potential confounders such as other umbilical fatty acids, type of postnatal feeding, the postnatal age of the infant at the time of follow-up assessment, paternal smoking, and the OOS. To calculate the effect of postnatal feeding, a dummy variable was created for the four following nutritional groups: LCPUFA formula, control formula, breast milk for $\leq 6$ wk, breast milk $>6$ wk. $p$ Values $<0.05$ were considered significant. Statistical analyses were performed using the statistical package for social sciences (SPSS 10; SPSS Inc., Chicago, IL).

\section{RESULTS}

Clinical neurologic classification. The umbilical fatty acids that were analyzed and related to neurodevelopmental outcome are presented in Table 3.

None of the participants of the study showed a definitely abnormal neurologic condition such as cerebral palsy. Two hundred ninety children had a normal neurologic condition (95\% of the study population) and 15 children had MND. The differences in fatty acid composition of the umbilical vein and artery between the neurologically normal children and those with MND are shown in Table 4. Children with MND had a significantly lower 20:0 content in their umbilical veins and arteries than neurologically normal children. Furthermore, trans, trans-18:2n-6 content in the umbilical vein was higher in children with MND than those in the normal group.

NOS. The correlation between the fatty acid composition of the umbilical vein and NOS is shown in Table 5. Univariate analysis revealed that $\mathrm{AA}$ in the umbilical vein showed a significantly positive relationship with NOS. The association was mainly explained by the difference in NOS between infants with umbilical vein AA content at or below the 50th percentile and those with umbilical vein AA content above the 50th percentile ( $p=0.02$, Fig. 2). The Spearman rank correlation did not reveal a relationship between DHA content of the umbilical vein and NOS (Table 5). However, closer in- 
Table 1. Social and perinatal characteristics of the infants

\begin{tabular}{|c|c|c|c|}
\hline & Study group & No samples or no NOS available & $p$ \\
\hline No. of infants (\%) & $290(61 \%)$ & $184(39 \%)$ & \\
\hline Male gender $(\%)$ & $55 \%$ & $52 \%$ & NS \\
\hline Birth weight, $g$ (mean $\pm \mathrm{SD})$ & $3547 \pm 430$ & $3533 \pm 501$ & NS \\
\hline Maternal age, $\mathrm{yr}(\mathrm{mean} \pm \mathrm{SD})$ & $30 \pm 4.2$ & $30 \pm 4.6$ & NS \\
\hline Maternal education: higher education (\%) & $22 \%$ & $20 \%$ & NS \\
\hline Paternal education: higher education (\%) & $22 \%$ & $26 \%$ & NS \\
\hline Maternal alcohol consumption during pregnancy $(\%)$ & $13 \%$ & $17 \%$ & NS \\
\hline Obstetric optimality score $($ mean \pm SD) & $62 \pm 3.7$ & $61 \pm 4.7$ & 0.05 \\
\hline
\end{tabular}

NS, not significant.

Table 2. Relationship between venous umbilical LCPUFAs, trans-fatty acids, and social economic characteristics

\begin{tabular}{|c|c|c|c|c|c|c|c|c|}
\hline & \multicolumn{2}{|c|}{ AA } & \multicolumn{2}{|c|}{ DHA } & \multicolumn{2}{|c|}{$\begin{array}{l}\text { Total c18 trans-fatty } \\
\text { acids }\end{array}$} & \multicolumn{2}{|c|}{ Total trans-fatty acids } \\
\hline & Median & Range & Median & Range & Median & Range & Median & Range \\
\hline Low & 16.51 & $11.1-19.9$ & 4.29 & $2.82-6.76$ & 0.176 & $0.04-1.14$ & 0.696 & $0.27-1.62$ \\
\hline High* $^{*}$ & 16.56 & $13.4-21.1$ & 4.23 & $2.93-7.47$ & 0.172 & $0.05-1.36$ & 0.739 & $0.32-1.94$ \\
\hline \multicolumn{9}{|c|}{ Paternal education } \\
\hline \multicolumn{9}{|c|}{ Maternal profession } \\
\hline Low & 16.53 & $11.1-21.1$ & 4.24 & $2.82-6.76$ & 0.171 & $0.04-1.32$ & 0.687 & $0.27-1.92$ \\
\hline $\mathrm{High}_{\dagger} \dagger$ & 16.48 & $13.4-19.8$ & $4.40 \ddagger$ & $3.14-7.47$ & 0.177 & $0.05-1.36$ & 0.739 & $0.33-1.94$ \\
\hline \multicolumn{9}{|c|}{ Paternal profession } \\
\hline Low & 16.61 & $11.1-19.8$ & 4.27 & $2.82-6.76$ & 0.168 & $0.04-1.14$ & 0.697 & $0.31-1.62$ \\
\hline $\mathrm{High} \dagger$ & 16.31 & $13.4-21.1$ & 4.27 & $3.07-7.47$ & 0.191 & $0.05-1.36$ & 0.714 & $0.27-1.94$ \\
\hline \multicolumn{9}{|c|}{ Maternal smoking during pregnancy } \\
\hline Yes & 16.54 & $11.7-19.9$ & 4.27 & $2.76-6.25$ & 0.161 & $0.04-0.57$ & 0.685 & $0.33-1.54$ \\
\hline \multicolumn{9}{|c|}{ Maternal alcohol use during pregnancy } \\
\hline No & 16.54 & $11.1-21.1$ & 4.24 & $2.82-6.76$ & 0.170 & $0.04-1.36$ & 0.691 & $0.27-1.94$ \\
\hline Yes & 16.26 & $13.9-19.8$ & 4.42 & $2.93-7.47$ & $0.200 \div$ & $0.10-0.70$ & 0.753 & $0.33-1.35$ \\
\hline
\end{tabular}

* University education or vocational college.

$\dagger$ Higher profession or independent middle class.

$\ddagger p<0.05$.

$\S p<0.01$.

Table 3. Fatty acid composition (\% by weight) of the umbilical wall of neurologically normal children and those with MND at 18 mo

\begin{tabular}{|c|c|c|c|c|c|}
\hline & \multicolumn{2}{|c|}{$\begin{array}{l}\text { Neurologically } \\
\text { normal children } \\
\quad(n=275)\end{array}$} & \multicolumn{2}{|c|}{$\begin{array}{l}\text { Children with MND } \\
\qquad(n=15)\end{array}$} & \multirow[b]{2}{*}{$p$} \\
\hline & Median \% & Range & Median \% & Range & \\
\hline \multicolumn{6}{|l|}{ Vein } \\
\hline 20:0 & 0.43 & $0.09-2.65$ & 0.36 & $0.18-0.44$ & 0.006 \\
\hline Trans, trans-18:2n-6 & 0.07 & $0.00-0.25$ & 0.10 & $0.03-0.16$ & 0.04 \\
\hline \multicolumn{6}{|l|}{ Artery } \\
\hline $20: 0$ & 0.50 & $0.04-2.90$ & 0.41 & $0.19-0.61$ & 0.02 \\
\hline
\end{tabular}

spection of the data indicated that infants with an umbilical vein DHA content within the lowest quartile had a significantly lower NOS than the other infants ( $p=0.02$, Fig. 2$)$. Multivariate analysis could not confirm the positive association between raw AA or dichotomized AA data and NOS. This approach did, however, confirm the association between the presence of umbilical vein DHA content in the lowest quartile and a lower NOS $(p=0.003$, standardized $\beta=0.17)$.

The sum of trans-fatty acids, the sum of $\mathrm{C} 18$ trans-fatty acids, and three individual trans-fatty acids of the umbilical vein showed significantly negative associations with NOS (Table 5, Fig. 2). The majority of these negative associations remained statistically significant in the multivariate analysis (Table 5). The negative association between the sum of transfatty acids and the NOS also remained statistically significant when we adjusted for DHA and AA content in the umbilical vein $(p=0.028$, standardized $\beta=-0.52)$ and when we repeated the analyses after exclusion of the breast-fed group $(p=0.007$, rho $=-0.20)$. The latter finding suggests that the association between trans-fatty acids and NOS may be attributed to prenatal and not postnatal trans-fatty acid exposure.

No associations between essential fatty acids, LCPUFAs, or trans-fatty acids in the umbilical artery and the NOS were found. 
Table 4. Relative fatty acid composition of the umbilical vein and artery

\begin{tabular}{|c|c|c|c|c|c|c|c|c|}
\hline \multirow[b]{2}{*}{ Fatty acid } & \multicolumn{4}{|c|}{ Vein } & \multicolumn{4}{|c|}{ Artery } \\
\hline & No. & $\begin{array}{c}\text { Median } \\
\% \text { of weight }\end{array}$ & Range & $\begin{array}{c}\% \text { below } \\
\text { detection limit }\end{array}$ & No. & $\begin{array}{c}\text { Median } \\
\% \text { of weight }\end{array}$ & Range & $\begin{array}{c}\% \text { below } \\
\text { detection limit }\end{array}$ \\
\hline $14: 0$ & 312 & 1.09 & $0.61-2.7$ & 0 & 307 & 1.28 & $0.64-2.2$ & 0 \\
\hline $15: 0$ & 312 & 0.73 & $0.23-4.5$ & 0 & 307 & 0.71 & $0.06-7.1$ & 0 \\
\hline $16: 0$ & 312 & 25.5 & $20.7-34.0$ & 0 & 307 & 23.6 & $19.8-38.4$ & 0 \\
\hline $18: 0$ & 312 & 18.1 & $14.4-23.1$ & 0 & 307 & 18.8 & $9.0-25.7$ & 0 \\
\hline $20: 0$ & 312 & 0.42 & $0.09-2.7$ & 0 & 307 & 0.50 & $0.04-2.9$ & 0 \\
\hline $22: 0$ & 312 & 0.97 & $0.33-2.4$ & 0 & 307 & 1.3 & $0.35-1.9$ & 0 \\
\hline $24: 0$ & 312 & 1.77 & $1.2-2.6$ & 0 & 307 & 2.4 & $1.0-3.7$ & 0 \\
\hline SAFAs & 311 & 48.6 & $44.8-61.8$ & & 307 & 48.8 & $43.7-58.8$ & \\
\hline $18: 3 n-3$ & 311 & 0.01 & $0.0-0.24$ & 0 & 306 & 0.01 & $0.0-0.17$ & 0 \\
\hline $20: 5 n-3$ & 311 & 0.01 & $0.0-0.14$ & 6.8 & 306 & 0.02 & $0.0-0.17$ & 4.9 \\
\hline $22: 5 n-3$ & 311 & 0.35 & $0.08-1.1$ & 0 & 306 & 0.31 & $0.08-0.77$ & 0 \\
\hline $22: 6 n-3$ & 311 & 4.3 & $2.8-7.5$ & 0 & 306 & 4.4 & $1.4-7.1$ & 0 \\
\hline Sum n-3 & 311 & 4.6 & $2.9-8.6$ & & 306 & 4.8 & $1.7-7.9$ & \\
\hline $18: 2 n-6$ & 311 & 2.6 & $1.4-4.0$ & 0 & 306 & 1.6 & $0.70-2.9$ & 0 \\
\hline $18: 3 n-6$ & 311 & 0.044 & $0.0-0.38$ & 0 & 306 & 0.07 & $0.0-0.74$ & 0 \\
\hline $20: 2 n-6$ & 311 & 0.35 & $0.04-0.94$ & 0 & 306 & 0.14 & $0.01-0.87$ & 0 \\
\hline $20: 3 n-6$ & 311 & 2.2 & $0.89-3.8$ & 0 & 306 & 1.5 & $0.73-2.8$ & 0 \\
\hline $20: 4 n-6$ & 311 & 16.5 & $11.1-21.1$ & 0 & 306 & 12.8 & $9.0-18.8$ & 0 \\
\hline $22: 4 n-6$ & 311 & 5.2 & $2.3-8.5$ & 0 & 306 & 3.0 & $1.5-5.6$ & 0 \\
\hline $22: 5 n-6$ & 311 & 2.9 & $1.4-4.7$ & 0 & 306 & 3.5 & $1.8-5.5$ & 0 \\
\hline Sum n-6 & 311 & 30.1 & $19.0-35.0$ & & 306 & 23.3 & $15.7-31.4$ & \\
\hline $16: 1 n-7$ & 311 & 0.53 & $0.22-1.1$ & 0 & 306 & 0.52 & $0.07-1.1$ & 0 \\
\hline $18: 1 n-7$ & 311 & 2.4 & $1.4-3.9$ & 0 & 306 & 2.8 & $1.7-3.8$ & 0 \\
\hline Sum n-7 & 311 & 2.9 & $1.8-4.4$ & & 306 & 3.3 & $2.0-4.4$ & \\
\hline $18: 1 n-9$ & 311 & 8.8 & $6.8-11.2$ & 0 & 306 & 11.5 & $7.9-16.4$ & 0 \\
\hline $20: 1 n-9$ & 311 & 0.36 & $0.06-3.9$ & 0 & 306 & 0.49 & $0.13-9.4$ & 0 \\
\hline $20: 3 n-9$ & 311 & 0.33 & $0.02-2.6$ & 0 & 306 & 2.6 & $0.46-5.8$ & 0 \\
\hline $22: 1 n-9$ & 311 & 0.04 & $0.0-0.20$ & 0 & 306 & 0.07 & $0.0-0.20$ & 0 \\
\hline $24: 1 n-9$ & 311 & 3.7 & $2.4-5.7$ & 0 & 306 & 3.9 & $2.3-5.6$ & 0 \\
\hline Sum n-9 & 311 & 13.5 & $9.7-20.2$ & & 306 & 18.8 & $11.1-26.0$ & \\
\hline TT18:2n-6 & 311 & 0.07 & $0.0-0.25$ & 0 & 306 & 0.09 & $0.0-0.30$ & 0.3 \\
\hline TC18:2n-6 & 311 & 0.01 & $0.0-0.17$ & 13.8 & 306 & 0.02 & $0.0-0.20$ & 13.7 \\
\hline CT18:2n-6 & 311 & 0.02 & $0.0-1.1$ & 0.3 & 306 & 0.04 & $0.0-2.1$ & 0.3 \\
\hline PT16:1n-7 & 311 & 0.50 & $0.11-1.2$ & 0 & 306 & 0.42 & $0.06-1.1$ & 0 \\
\hline PT18:1n-9/7 & 311 & 0.06 & $0.01-0.29$ & 0 & 306 & 0.05 & $0.0-0.25$ & 0 \\
\hline Sum trans & 311 & 0.70 & $0.27-1.9$ & & 306 & 0.67 & $0.35-2.8$ & \\
\hline C18 trans & 311 & 0.17 & $0.04-1.4$ & & 306 & 0.22 & $0.04-2.3$ & \\
\hline MUFAs & 311 & 16.8 & $12.5-21.3$ & & 306 & 19.9 & $13.7-26.0$ & \\
\hline LCPUFAs & 311 & 32.2 & $20.2-36.5$ & & 306 & 28.8 & $20.7-34.1$ & \\
\hline
\end{tabular}

Values are percentage by weight. SAFAs, saturated fatty acids; MUFAs, monounsaturated fatty acids.

Bayley Scales of Infant Development. Neither univariate nor multivariate analyses revealed significant associations between AA, DHA, and total trans-fatty acids in the umbilical walls of artery or vein and the Bayley PDI and MDI (Fig. 2).

\section{DISCUSSION}

The present study indicated that, in healthy term infants, a DHA content in the umbilical vein within the lowest quartile and a higher content of venous trans-fatty acids were associated with a less optimal neurologic condition at $18 \mathrm{mo}$. This effect was found with the Hempel technique but could not be demonstrated with psychomotor or mental development indices of the Bayley scales. This underscores the notion that the Hempel technique is a more sensitive instrument to assess possibly subtle effects of early nutritional condition on brain function than the Bayley scales, which are designed to detect major developmental delays (23).

Our study indicates that low prenatal venous umbilical DHA content is associated with a less optimal neurologic condition at $18 \mathrm{mo}$. In the same study cohort as in the present study, we previously found that DHA and AA content in the umbilical vein was associated with a more optimal neurologic condition on postnatal d 10-14 (8). In addition, we found that neonatal AA content in the umbilical artery was related to a better neurologic condition at $3 \mathrm{mo}$, whereas DHA affected neurologic condition at 3 mo to a marginal extent (9).

At 18 mo of age, we found the opposite: neonatal DHA content of the umbilical cord showed a significant correlation with neurologic optimality, whereas neonatal umbilical AA content only had a marginal effect on neurologic outcome. Taken together these findings suggest that both neonatal AA and DHA status might affect neurologic development to a limited extent. This could explain why previous studies produced conflicting results. Two studies that evaluated cognitive function in similarly large populations of full-term infants could not establish a relationship between neonatal LCPUFA status and cognitive function at 4 and $7 \mathrm{y}(10,11)$. On the other hand, two supplementation studies with DHA during pregnancy found that a higher neonatal DHA status was positively associated with more mature electroencephalographic scores 
Table 5. Correlations between the fatty acid composition (\% by weight) of the umbilical vein and the NOS at $18 \mathrm{mo}$

\begin{tabular}{|c|c|c|c|c|}
\hline & \multicolumn{4}{|c|}{ NOS } \\
\hline & \multicolumn{2}{|c|}{ Univariate analysis } & \multicolumn{2}{|c|}{ Multivariate analysis } \\
\hline & $\begin{array}{l}\text { Spearman's } \\
\text { rho }\end{array}$ & $p$ & $\begin{array}{l}\text { Standardized } \\
\text { coefficient }(\beta)\end{array}$ & $p$ \\
\hline \multicolumn{5}{|l|}{ Vein } \\
\hline Saturated & - & NS & - & NS \\
\hline Monounsaturated & - & NS & - & NS \\
\hline \multicolumn{5}{|l|}{ Omega-6 } \\
\hline $20: 4 n-6$ & 0.13 & 0.03 & - & NS \\
\hline \multicolumn{5}{|l|}{ Omega-3 } \\
\hline $22: 6 n-3$ & - & NS & - & NS \\
\hline Total trans-fatty acids & -0.23 & $<0.0005$ & -0.52 & 0.03 \\
\hline C18 trans-fatty acids & -0.19 & 0.0001 & -0.16 & 0.02 \\
\hline Trans- $18: 1 \mathrm{n}-9$ or 7 & -0.12 & 0.04 & - & NS \\
\hline Trans,cis-18:2n-6 & -0.21 & $<0.005$ & -0.20 & 0.001 \\
\hline Trans-16:1n-7 & -0.12 & 0.048 & -0.14 & 0.02 \\
\hline
\end{tabular}

Factors that played an additional significant role in at least one of the multivariate models were education of the father, HOME score, weight of gravida before pregnancy, uncertain or unreliable date of last menstrual period, breast-feeding for more than $6 \mathrm{wk}$, and age of assessment at $18 \mathrm{mo}$. Allocation into control formula or LCPUFA-supplemented formula group and primi- versus multiparity did not affect NOS significantly.

on the second day of life and latencies to visual evoked potentials recorded to pattern-reversal stimuli at $10 \mathrm{wk}$ and 6 mo $(29,30)$. Previous studies indicated that postnatal supplementation with DHA affects neurologic condition during early infancy, but not neurodevelopmental outcome at 1-3 y $(24,31,32)$. In the present population, we also did not find an effect of breast-feeding or LCPUFA-enriched formula on neurologic condition at 18 mo (24). The present study demonstrated that the association of prenatal DHA with neurodevelopmental outcome was not restricted to early infancy, but was still demonstrable at the age of $18 \mathrm{mo}(8,30,33)$. Although the association was relatively small, it remained present when we took into account the effect of postnatal LCPUFA supplementation. This suggests that in terms of neurologic health prenatal DHA status is more important than postnatal DHA status. This underscores the notion that we should pay attention to the essential fatty acid status of pregnant women, in particular of multiparous women $(34,35)$.

The association between venous umbilical DHA content and NOS was not a linear one, but showed a threshold effect. Animal studies suggest that low DHA status results in deviant behavior. n-3 LCPUFA-deficient rhesus monkeys showed more stereotyped motor behavior than control animals fed a matched control diet abundant in n-3 fatty acids (36). In rats, low brain content of DHA induces altered dopaminergic function and behavior (37).

Surprisingly, we found that the venous umbilical trans-fatty acid content was more prominently associated with neurodevelopmental outcome at 18 mo than LCPUFA content, an association that was statistically independent of DHA and AA content of the umbilical vein. This negative association remained statistically significant when we excluded the breastfed infants from the analyses to evaluate whether the association still persists without potential postnatal trans-fatty supply via breast-feeding. Before addressing the putative bi-
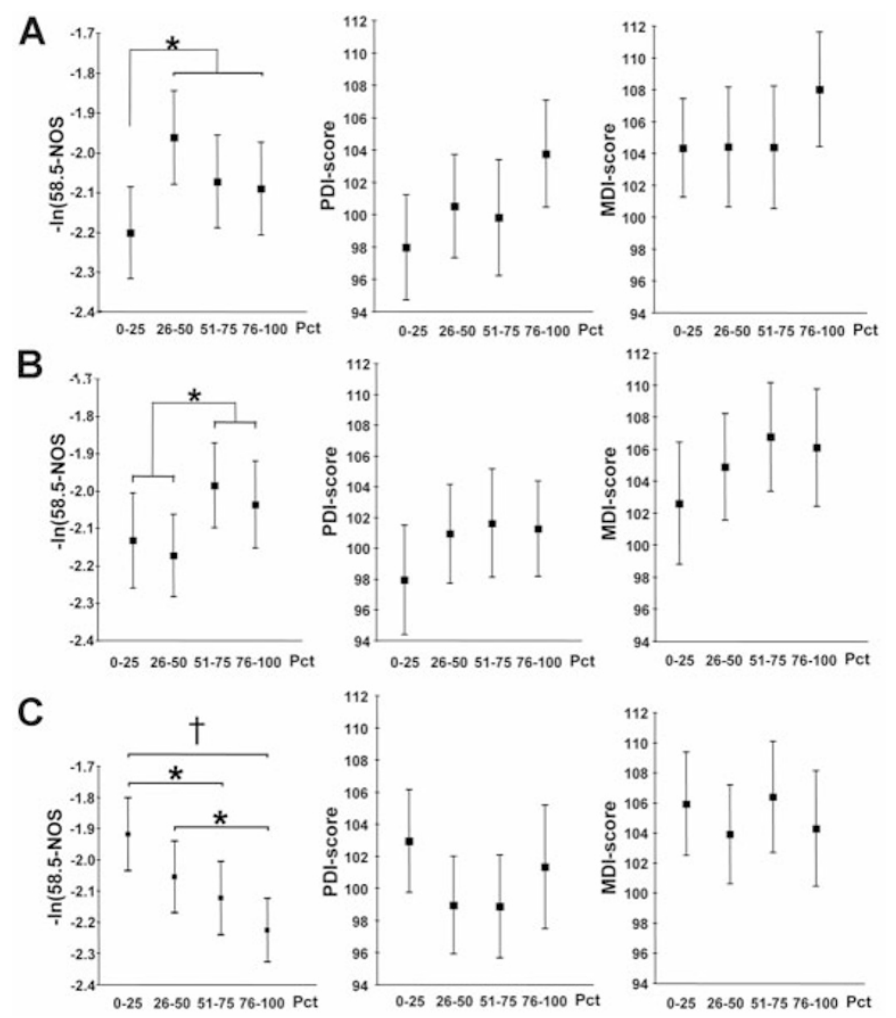

Figure 2. Relationships between umbilical vein content of DHA $(A)$, AA $(B)$ and the sum of trans-fatty acids $(C)$ expressed in quartiles and NOS and PDI and MDI scores. The NOS is expressed in the transformed NOS, which was used to achieve gaussian distribution. Note that a higher $-\ln (58.5-$ NOS) value means a better NOS. The squares denote mean values, the vertical bars the 95\% confidence interval of the mean. Asterisks denote statistically significant differences between groups in the univariate analyses (Mann-Whitney $U$ test): ${ }^{*} p<0.05, \dagger p<0.001$.

ologic mechanisms underlying this finding, we emphasize that we cannot exclude that a certain but small amount of all trans-fatty acids present were not analyzed, e.g. the longer chain trans-fatty acids. Thus, we found a negative correlation between the lion's share of trans-fatty acids and neurologic condition at 18 mo. Because trans-fatty acids cannot be synthesized de novo, the content of trans-fatty acids in the umbilical wall reflects maternal dietary intake of trans-fatty acids. Trans-fatty acid can potentially alter numerous cell membrane properties when incorporated in membranes (38); however, no significant in vivo incorporation of trans-fatty acids in the neuronal membranes takes place (16). Despite the minor effects of trans-fatty acids on the fatty acid composition of neuronal membranes, high trans-fatty diets do induce dopaminergic alterations in the brains of pigs and rats $(39,40)$. The biochemical mechanisms are not yet clear, but it seems unlikely that the biochemical effects of trans-fatty acids are mediated by neuronal membrane function. It has been shown that fatty acids can alter gene transcription that impacts lipid, carbohydrate, and protein metabolism as well as cell growth and differentiation via several transcription factors in the cytoplasm and cell nucleus (4). It could be that some specific trans-fatty acids such as conjugated trans-fatty acids by means of interaction with peroxisome proliferator-activated receptors (PPARs) might induce unfavorable neuronal func- 
tion. To our knowledge, no data are available on the effects of trans-fatty acids on neurodevelopmental outcome $(14,16)$. Such knowledge is urgently needed as it is possible that humans are more vulnerable to early trans-fatty acid exposure than animals. This is suggested by the finding that trans-fatty acids do not affect birth weight, growth, and longevity in animals $(14,41)$, whereas in human preterm infants, trans-fatty acids are negatively correlated to birth weight (12).

Besides the direct potential harmful effects of trans-fatty acids on neurodevelopment, we originally assumed that transfatty acids could also be indicators of the presence of less favorable dietary constituents in general, which in turn could be associated with a lower socioeconomic status. However, our data indicated that higher trans-fatty content to a limited extent was even related to a higher social class as indicated by the father's profession (Table 2). A recent report of the Dutch Ministry of Health, Welfare, and Sports indicated that the intake of trans-fatty acids among Dutch young adults was not related to socioeconomic characteristics (17). These findings do not exclude the possibility that a higher trans-fatty acid intake may be associated with an unhealthy diet or lifestyle. To illustrate the point, the consumption of a diet rich in trans-fatty acid content has been associated with bakery products, confectionery, and snacks (42).

In conclusion neonatal DHA status, used as a proxy of maternal supply during pregnancy, has a small but statistically significant beneficial effect on neurologic condition at $18 \mathrm{mo}$. In addition, neonatal trans-fatty acid status has a substantial negative effect on neurologic condition at $18 \mathrm{mo}$. The latter finding might support a plea for the removal of the industrially produced trans-fatty acids from our diet.

Acknowledgments. We gratefully acknowledge the statistical advice of Dr. M. R. Fokkema.

\section{REFERENCES}

1. Lauritzen L, Hansen HS, Jorgensen MH, Michaelsen KF 2001 The essentiality of long chain $n-3$ fatty acids in relation to development and function of the brain and retina. Prog Lipid Res 40:1-94

2. Innis SM 1991 Essential fatty acids in growth and development. Prog Lipid Res 30:39-103

3. Hulbert AJ, Else PL 1999 Membranes as possible pacemakers of metabolism. J Theor Biol 199:257-274

4. Jump DB 2004 Fatty acid regulation of gene transcription. Crit Rev Clin Lab Sci 41:41-78

5. Martinez M, Mougan I 1998 Fatty acid composition of human brain phospholipids during normal development. J Neurochem 71:2528-2533

6. Farquharson J, Cockburn F, Patrick WA, Jamieson EC, Logan RW 1992 Infant cerebral cortex phospholipid fatty-acid composition and diet. Lancet 340:810-813

7. Koletzko B, Müller J 1990 Cis- and trans-isomeric fatty acids in plasma lipids of newborn infants and their mothers. Biol Neonate 57:172-178

8. Dijck-Brouwer DA, Hadders-Algra M, Bouwstra H, Decsi T, Boehm G, Martini IA, Boersma ER, Muskiet FA 2005 Lower fetal status of docosahexaenoic acid, arachidonic acid and essential fatty acids is associated with less favorable neonatal neurological condition. Prostaglandins Leukot Essent Fatty Acids 72:21-28

9. Bouwstra H, Dijck-Brouwer DA, Decsi T, Boehm G, Boersma ER, Muskiet FA, Hadders-Algra M. Relationship between umbilical cord essential fatty acid content and the quality of general movements or healthy term infants at 3 months. Pediatr Res 59:717-722.

10. Ghys A, Bakker E, Hornstra G, van den Hout M 2002 Red blood cell and plasma phospholipid arachidonic and docosahexaenoic acid levels at birth and cognitive development at 4 years of age. Early Hum Dev 69:83-90

11. Bakker EC, Ghys AJ, Kester AD, Vles JS, Dubas JS, Blanco CE, Hornstra G 2003 Long-chain polyunsaturated fatty acids at birth and cognitive function at $7 \mathrm{y}$ of age. Eur J Clin Nutr 57:89-95

12. Koletzko B 1992 Trans fatty acids may impair biosynthesis of long-chain polyunsaturates and growth in man. Acta Paediatr 81:302-306
13. Decsi T, Koletzko B 1995 Do trans fatty acids impair linoleic acid metabolism in children. Ann Nutr Metab 39:36-41

14. Carlson SE, Clandinin MT, Cook HW, Emken EA, Filer LJ Jr 1997 trans fatty acids: infant and fetal development. Am J Clin Nutr 66:715S-736S

15. Stender S, Dyerberg J, Holmer G, Ovesen L, Sandstrom B 1995 The influence of trans fatty acids on health: a report from the Danish Nutrition Council. Clin Sci 88:375-392

16. Larqué E, Zamora S, Gil A 2001 Dietary trans fatty acids in early life: a review. Early Hum Dev 65:S31-S41

17. Hulshof KF, Ocke MC, van Rossum CT, Buurma-Rethans EJ, Brants HA, Drijvers JJ, ter Doest D 2003 Results of the national food consumption survey 2003. RIVM report 350030002/2004. Available at: http://www.rivm.nl/bibliotheek/rapporten/ 350030002.pdf (accessed 2004).

18. Bouwstra H, Dijck-Brouwer DA, Wildeman JA, Tjoonk HM, van der Heide JC, Boersma ER, Muskiet FA, Hadders-Algra M 2003 Long-chain polyunsaturated fatty acids have a positive effect on the quality of general movements of healthy term infants. Am J Clin Nutr 78:313-318

19. Muskiet FA, van Doormaal JJ, Martini IA, Wolthers BG, van der Slik W 1983 Capillary gas chromatographic profiling of total long-chain fatty acids and cholesterol in biological materials. J Chromatogr 278:231-244

20. Decsi T, Boehm G, Tjoonk HM, Molnar S, Dijck-Brouwer DA, Hadders-Algra M, Martini IA, Muskiet FA, Boersma ER 2002 Trans isomeric octadecenoic acids are related inversely to arachidonic acid and DHA and positively related to mead acid in umbilical vessel wall lipids. Lipids 37:959-965

21. Decsi T, Burus I, Molnar S, Minda H, Veitl V 2001 Inverse association between trans isomeric and long-chain polyunsaturated fatty acids in cord blood lipids of full-term infants. Am J Clin Nutr 74:364-368

22. Hempel MS 1993 Neurological development during toddling age in normal children and children at risk of developmental disorders. Early Hum Dev 34:47-57

23. Hadders-Algra M 2005 The neuromotor examination of the preschool child and its prognostic significance. Ment Retard Dev Disabil Res Rev 11:180-188

24. Bouwstra H, Dijck-Brouwer DA, Boehm G, Boersma ER, Muskiet FA, Hadders-Algra M 2005 Long-chain polyunsaturated fatty acids and neurological developmental outcome at 18 months in healthy term infants. Acta Paediatr 94:26-32

25. Bayley N 1993 Bayley Scales of Infant Development. Psychological Corporation, San Antonio

26. Van der Meulen BF, Ruiter SA, Spelberg HC, Smrkovsky M 2002 Bayley Scales of Infant Development-II. [Dutch version of the BSID-II; specific Dutch norms included]. Nederlandse versie. Swets Test Publishers, Lisse

27. Touwen BC, Huisjes HJ, Jurgens-Van der Zee AD, Bierman-van Eendenburg ME, Smrkovsky M, Olinga AA 1980 Obstetrical condition and neonatal neurological morbidity. An analysis with the help of the optimality concept. Early Hum Dev 4:207-228

28. Bradley RH, Caldwell BM, Brisby J, Magee M, Whiteside L, Rock SL 1992 The HOME inventory: a new scale for families of pre- and early adolescent children with disabilities. Res Dev Disabil 13:313-333

29. Helland IB, Saugstad OD, Smith L, Saarem K, Solvoll K, Ganes T, Drevon CA 2001 Similar effects on infants of $\omega 3$ and $\omega 6$ fatty acids supplementation to pregnant and lactating women. Pediatrics 108:E82-

30. Malcolm CA, McCulloch DL, Montgomery C, Shepherd A, Weaver LT 2003 Maternal docosahexaenoic acid supplementation during pregnancy and visual evoked potential development in term infants: a double blind, prospective, randomized trial. Arch Dis Child Fetal Neonatal Ed 88:F383-F390

31. Simmer K 2001 Longchain polyunsaturated fatty acid supplementation in infants born at term. Cochrane Database Syst Rev 200132 CD000376

32. Agostoni C, Trojan S, Bellu R, Riva E, Bruzzese MG, Giovannini M 1997 Developmental quotient at 24 months and fatty acid composition of diet in early infancy: a follow up study. Arch Dis Child 76:421-424

33. Helland IB, Smith L, Saarem K, Saugstad OD, Drevon CA 2003 Maternal supplementation with very-long-chain n-3 fatty acids during pregnancy and lactation augments children's IQ at 4 years of age. Pediatrics 111:e39-e44

34. Al MD, van Houwelingen AC, Hornstra G 2000 Long-chain polyunsaturated fatty acids, pregnancy, and pregnancy outcome. Am J Clin Nutr 71:285S-291S.

35. Smit EN, Muskiet FA, Boersma ER 2004 The possible role of essential fatty acids in the pathophysiology of malnutrition: a review. Prostaglandins Leukot Essent Fatty Acids 71:241-250

36. Reisbick S, Neuringer M, Hasnain R, Connor WE 1994 Home cage behavior of rhesus monkeys with long-term deficiency of omega-3 fatty acids. Physiol Behav 55:231-239

37. Levant B, Radel JD, Carlson SE 2004 Decreased brain docosahexaenoic acid during development alters dopamine-related behaviors in adult rats that are differentially affected by dietary remediation. Behav Brain Res 152:49-57

38. Roach C, Feller SE, Ward JA, Shaikh SR, Zerouga M, Stillwell W 2004 Comparison of cis and trans fatty acid containing phosphatidylcholines on membrane properties. Biochemistry 43:6344-6351

39. Acar N, Chardigny JM, Berdeaux O, Almanza S, Sebedio JL 2002 Modification of the monoaminergic neurotransmitters in frontal cortex and hippocampus by dietary trans alpha-linolenic acid in piglets. Neurosci Lett 331:198-202

40. Acar N, Chardigny JM, Darbois M, Pasquis B, Sebedio JL 2003 Modification of the dopaminergic neurotransmitters in striatum, frontal cortex and hippocampus of rats fed for 21 months with trans isomers of alpha-linolenic acid. Neurosci Res 45:375-382

41. Opstvedt J, Pettersen J, Mork SJ 1988 Trans fatty acids. 1. Growth, fertility, organ weights and nerve histology and conduction velocity in sows and offspring. Lipids 23:713-719

42. Mojska H, Socha P, Socha J, Soplińska E, Jaroszewska-Balicka W, Szponar L 2003 Trans fatty acids in human milk in Poland and their association with breastfeeding mothers' diets. Acta Paediatr 92:1381-1387 